\title{
A IMAGEM ESTEREOTIPADA DO IDOSO E A NECESSIDADE DE SE ENGENDRAR INTERVENÇÕES PARA ALÉM DA ENFERMIDADE
}

\author{
THE STEREOTYPED IMAGE OF THE ELDERLY AND THE NEED \\ TO BECOME INTERVENTIONS BEYOND DISEASE
}

\author{
Autores * \\ Elaine de Deus Oliveira ${ }^{1}$ \\ Geovane de Souza Corrêa ${ }^{2}$ \\ Marta Jéssica de Oliveira Paiva ${ }^{3}$
}

\section{RESUMO}

Este artigo tem como objetivo integrar reflexões a respeito do processo de envelhecimento e a necessidade de intervenções para além da enfermidade. $O$ critério metodológico empregado foi a consulta sistêmica de materiais bibliográficos utilizando referenciais no tema, tais como, Geib (2012); Oliveira (2012); Veras (2012); Cunha (2014) entre outros, somados a vivência da pesquisa-participante de campo realizada numa Instituição de Longa Permanência para Idosos em Nova Friburgo (RJ). O artigo aborda: Noções de saúde e política de cuidados aos idosos; A velhice no Brasil; Novas perspectivas sobre o envelhecimento; Principais desordens das quais o idoso pode ser acometido; e, Musicoterapia: uma terapia alternativa. O resultado obtido na prática do Projeto "Vidas que Tocam" veio pelo investimento em estratégias de prevenção para um envelhecimento saudável e melhor qualidade de vida, ao apresentar uma intervenção com músicas. Portanto, a musicoterapia é considerada uma atividade benéfica e prazerosa ao acesso à memória dos idosos institucionalizados por proporcionar-lhes um vislumbre na memória de uma época bem vivida.

Palavras-chave: Velhice. Idoso. Saúde. Enfermidade. Intervenção. Musicoterapia.

\footnotetext{
* Formandos do Curso de Psicologia da Universidade Estácio de Sá. Campus - Nova Friburgo, RJ. 2018 Supervisora: Prof ${ }^{a}$. Hellena Alves Jacone. E-mail: hellena.jacone@estacio.br

${ }^{1}$ E-mail: oliveira.elainededeus@gmail.com

${ }^{2}$ E-mail: psico.geovane@gmail.com

${ }^{3}$ E-mail: martajessica.paiva@hotmail.com
} 


\begin{abstract}
This article aims to integrate reflections on the aging process and the need for interventions beyond the disease. The methodological criterion used was the systemic consultation of bibliographic materials using references on the theme, such as Geib (2012); Oliveira (2012); Veras (2012); Cunha (2014), among others, added to the experience of field participant research conducted in a Long Term Care Institution for the Elderly in Nova Friburgo (RJ). The article deals with: Notions of health and care policy for the elderly; Old age in Brazil; New perspectives on aging; Main disorders of which the elderly can be affected; and Music therapy: an alternative therapy. The result obtained in the practice of the project "Lives That Touch" came from investing in prevention strategies for a healthy aging and better quality of life, by presenting an intervention with songs. Therefore, music therapy is considered a beneficial and pleasurable activity to access the memory of institutionalized elderly people by providing them with a glimpse into the memory of a well-lived time.
\end{abstract}

Keywords: Old age. Old man. Health. Illness. Intervention. Music Therapy. 


\section{A IMAGEM ESTEREOTIPADA DO IDOSO E A NECESSIDADE DE SE ENGENDRAR INTERVENÇÕES PARA ALÉM DA ENFERMIDADE}

\section{INTRODUÇÃO}

Esse artigo é resultado de um Projeto de Extensão realizado por alunos (formandos) do Curso de Psicologia da Universidade Estácio de Sá, Campus Nova Friburgo (RJ), que teve por desígnio compartilhar uma prática possível: Aproximar a teoria da prática.

Através da pesquisa participante, de caráter qualitativo, uma equipe de alunos foi à campo, sob supervisão, aplicar o Projeto "Vidas que Tocam", fruto da disciplina de Desenvolvimento Humano III $^{4}$ cuja temática aborda o envelhecimento humano. A equipe buscou uma vivência que permitisse enfrentar um grande desafio que perpassa a maioria dos cursos universitários, que é aproximar, ao máximo possível, as informações acadêmicas e teorias transmitidas em sala de aula com a realidade vivida em nossa sociedade.

Baseada nos trabalhos de Pestana e Espírito Santo (2008), a pesquisa reforça a velhice como sendo um processo social e que precisa ser vista como parte da vida, pois se trata de uma fase com mudanças psicológicas, físicas e sociais, na qual cada um, de forma particular, olha para todas as conquistas e perdas de sua existência, onde numa sociedade norteada pelo capitalismo somente é valorizado o homem produtivo. A velhice passa a ser vista de forma negativa e é marginalizada.

Todavia, Lima-Costa, Barreto e Giatti (2003) dizem que para a realização de um trabalho local com intervenções na saúde do idoso, torna-se necessário que se façam estudos epidemiológicos de base populacional na comunidade. No entanto, a pesquisa bibliográfica realizada para a elaboração deste artigo evidenciou que o crescimento da população idosa não tem sido acompanhado por tais estudos na mesma proporção. Diversos estudos brasileiros na área da saúde sempre excluíram ou trataram essa população com mais de 60 ou 65 anos como um grupo homogêneo.

Estudos científicos, nos campos da Sociologia e Psicologia, confirmam que muitos idosos são abandonados em Instituições de Longa Permanência para Idosos, perdendo o vínculo familiar parcial ou totalmente e, muitas vezes, com a sua própria história. Considerando essa conjuntura, o Projeto teve por finalidade resgatar lembranças da história

\footnotetext{
${ }^{4}$ Prof ${ }^{\mathrm{a}}$. Hellena Alves Jacone.
} 
das idosas institucionalizadas que participaram do projeto na ILPIs em Nova Friburgo (RJ), pelo viés da musicoterapia, proporcionando um vislumbre em suas memórias de uma época vivida e, dessa forma, contribuir para a saúde e bem-estar delas.

\section{A VELHICE NO BRASIL}

Segundo Barros e Gomes Junior (2003), houve uma evolução da população brasileira com mais de 60 anos desde a década de 1960. A expectativa de vida aumentou e deverá crescer ainda mais nos próximos anos. Este aumento foi possível devido à chegada de tecnologias importadas na área da saúde, que reduziram a mortalidade e permitiram a cura de doenças contagiosas, mesmo em populações que vivem em más condições e que recebem salários insuficientes para a satisfação de necessidades básicas.

Observa-se também o fenômeno da 'feminização da velhice', ou seja, a maior parte da população idosa é de mulheres que, em média, vivem 8 anos a mais que os homens, pois entre elas é maior a procura por acompanhamentos médicos durante a vida, e em mais de $90 \%$ dos casos de mortes violentas por acidente ou assassinato as vítimas são homens (KÜCHEMANN, 2012).

Geib (2012) aponta a desigualdade de renda como um dos fatores que influenciam na saúde dos idosos. Além disso, a desigualdade de gênero restringe a participação das idosas no mercado de trabalho. Devido a estes aspectos, a globalização e a crise econômica internacional de 2008, há ameaça de desemprego e dificuldades de acesso da população idosa ao sistema de seguridade e à assistência em saúde. Segundo a autora (Id., p. 127):

\footnotetext{
A ameaça de exclusão social dos idosos por déficit na seguridade social constitui um poderoso determinante social de saúde, que inter-relacionado com baixa renda, moradia precária, insegurança alimentar e medicamentosa, entre outros, pode afetar negativamente a saúde dos idosos brasileiros e tornar-se um dos principais fatores de morbidade prematura e mortalidade por doenças crônicas como cardiopatias, acidentes vasculares e diabetes.
}

De acordo com a Constituição de 1988 e o Estatuto do Idoso de 2003 é responsabilidade da família, da sociedade e do Estado dar suporte aos idosos e idosas. No entanto, apesar de o Estado prover alguns recursos, a oferta e cobertura de serviços são insuficientes. Há poucos serviços de atenção integral e residências ou centros de recreação, que ficam restritos a setores de nível socioeconômico mais alto (KÜCHEMANN, 2012). 


\section{PRINCIPAIS DESORDENS DAS QUAIS O IDOSO PODE SER ACOMETIDO}

Consoante com Cortê e Neto (2008), ao falar de idoso, já são evocadas em nossa mente doenças degenerativas como se uma coisa estivesse relacionada a outra de forma inevitável ou inseparável. Segundo esses autores, essa lógica de raciocínio se dá pelo fato de que mesmo que doenças como Alzheimer, Parkinson ou outras complicações possam acometer pessoas mais jovens, a incidência em pessoas mais velhas é bem maior e, por essa razão, logo se faz uma correlação entre idade cronológica e doenças degenerativas. Assim como Veras (2012), Cortê e Neto (2008) também acreditam numa abordagem na qual o foco não deve ser a doença e seus sintomas; o foco deve estar para além disso, para o principal - o sujeito. A direção do tratamento deve se pautar na relação que o sujeito tem com sua doença e com o outro.

A doença de Parkinson (DP) é caracterizada principalmente por desordens motoras, uma vez que essa doença atinge essencialmente o sistema motor. Uma pessoa acometida pela DP pode apresentar enrijecimento corporal e do rosto, parar de repente em meio a uma ação, dificuldade de se equilibrar, de andar, falar ou escrever, ter acinesia, etc. Entretanto, efeitos de ordem não motora também são manifestados como: perda de memória, alterações emocionais, distúrbios cognitivos e do sono, dores, entre outros efeitos. (CORTÊ; NETO, 2008).

A doença de Alzheimer é uma doença irreversível e degenerativa do sistema nervoso. Ela atinge o hipocampo, uma área do cérebro responsável por funções cognitivas como a memória, pensamento e linguagem e conforme a doença avança o comprometimento dessas funções se intensificam cada vez mais. Oliveira (et al., 2012) aponta que os danos causados em decorrência desse comprometimento trazem prejuízo significativo para a vida do sujeito acometido por Alzheimer, uma vez que interfere também na sua vida social e a dificuldade de se comunicar e de interagir socialmente pode resultar em estados depressivos. "A Doença de Alzheimer constitui a forma mais comum de demência em idosos. Atualmente atinge de 17 a 25 milhões de pessoas no mundo, considerando-se sua incidência em um a 1,5\% das pessoas entre 60 e 65 anos, e em $45 \%$ após os 95 anos." (ALBUQUERQUE et al., 2012, p. 405).

Segundo Camões (et al., 2005) A doença de Alzheimer avança de forma que o sujeito acometido por ela seja privado de todas as atividades mentais. No começo, geralmente em torno dos 55 anos de idade, ocorrem pequenos lapsos de memória que são ignorados a priori mas, a posteriori incomodam porque o sujeito começa a ficar desorientado quanto a si mesmo (memória autobiográfica), no tempo e no espaço, esquece nomes de pessoas (memória social) e coisas. A manifestação de comportamentos anormais também aparecem com o avanço da 
doença como episódios de agressividade, indiferença afetiva, alucinações e dificuldade ou incapacidade para se vestir, comer, etc.. Como não existe cura para o Alzheimer, o tratamento deve ser feito numa perspectiva abrangente, ou seja, com todos os recursos disponíveis e possíveis que visem minimizar os impactos causados pela doença e retardar a deterioração cognitiva. Os recursos podem ser a medicação, apoio psicossocial, psicoterapia e terapias alternativas como a musicoterapia, por exemplo.

Pode a música ser trabalhada em grupo (em um coral ou um conjunto musical), como forma de promover a socialização, ou de forma individual, explorando a criatividade e a manifestação subjetiva. O processo utilizado para um tratamento sustentado pela musicoterapia é variável de indivíduo a indivíduo, de acordo com as características de cada história de vida, que é única, pessoal e original. A importância da música em diferentes problemas neurológicos vem sendo destacada por vários autores na atualidade. (CORTÊ; NETO, 2008, p. 6)

Outro fator de risco que figura como um dos principais relacionados à saúde do idoso, no âmbito da saúde pública, é a hipertensão arterial sistêmica. A hipertensão tem alta prevalência e dificuldade de controle e, em decorrência disso, as implicações para pessoas com hipertensão são variadas e estão sujeitas à possibilidade de infarto do coração, AVC, problemas renais, sexuais, dentre outras complicações, e a musicoterapia como intervenção complementar, não medicamentosa, pode trazer benefícios para a saúde do hipertenso pois é capaz de reduzir a pressão arterial (SANTANA et al., 2014).

A utilização da música como ferramenta complementar ou alternativa engendra efeitos extraordinários nos mais variados tipos de adoecimento. De acordo com Don Campbell e Oliver Sacks conforme citado por Cortê e Neto (2008, p. 6) "A música atinge, misteriosamente, as profundezas de nosso cérebro e nosso corpo, despertando muitos sistemas inconscientes" e "O poder da música para integrar e curar [...] é fundamental. Ela é o mais profundo medicamento não-químico".

Albuquerque et al. (2012, p. 405) afirmam que:

A música envolve o ser humano em dinâmicas psicológicas e fisiológicas, tem a capacidade de estruturar e comunicar pensamentos e emoções nos âmbitos da vida individual e coletiva [...] ela atinge todo o organismo, provocando efeitos de âmbito biológico, fisiológico, psicológico, intelectual, social e espiritual, agindo de maneira significativa no sistema nervoso, respiratório, circulatório, digestivo e metabólico [...] Seu uso tem efeitos duradouros, melhora o humor, o comportamento e a função cognitiva, estes persistem por horas ou dias depois de terem sido desencadeados pela mesma. É um recurso de grande importância na atenção aos idosos, pois estimula o prazer do convívio social, influência nas mudanças comportamentais, deixando-os mais atuantes e proporciona-lhes a sensação de conforto, paz, tranquilidade e confiança. 
Intervenções através da musicoterapia têm sido relatadas em profusos estudos quanto aos seus resultados e neles podemos constatar êxitos no que concerne à motricidade, à afetividade, inibição, ao resgate de memórias, redução de dores musculares etc.

\section{NOVAS PERSPECTIVAS SOBRE O ENVELHECIMENTO}

Segundo a Organização mundial de saúde - OMS (2005) até o ano de 2025 o Brasil será detentor da sexta população com maior número de idosos do mundo e o que preocupa não é apenas o crescimento dessa população, mas, sim, a falta de informação da sociedade quanto aos desafios oriundos do envelhecimento populacional, tal como as dificuldades no âmbito da saúde pública.

Numa tentativa de resolver esse imbróglio, a OMS elaborou um documento informativo chamado de "Envelhecimento saudável - Uma política de saúde". Esse documento define que a saúde deve ser vista de forma abrangente e isso deve ser feito através de um trabalho inter e transdisciplinar, de modo a promover qualidade de vida em todas as idades e que cabe aos profissionais de saúde transpor esses desafios para que o idoso seja reconhecido como "um recurso valioso para a suas famílias, comunidades e para o país".

\footnotetext{
Em todo o mundo, a proporção de pessoas com 60 anos ou mais está crescendo mais rapidamente que a de qualquer outra faixa etária. Entre 1970 e 2025, espera-se um crescimento de $223 \%$, ou em torno de 694 milhões, no número de pessoas mais velhas. Em 2025, existirá um total de aproximadamente 1,2 bilhões de pessoas com mais de 60 anos. Até 2050 haverá 2 bilhões, sendo $80 \%$ nos países em desenvolvimento. (OMS, 2005)
}

Diante desses números expressivos a OMS adotou o termo "envelhecimento ativo" ao qual considera a importância do envolvimento contínuo de pessoas mais velhas em questões sociais, econômicas, culturais e civis. Considera ativos não somente aqueles que podem trabalhar, que têm autonomia e que vivem sem maiores necessidades de cuidados médicos e assistenciais, mas, também, aqueles que são frágeis e que requerem cuidados mais enérgicos, uma vez que independentemente de sua condição o idoso pode contribuir de algum modo para sua família ou para sua comunidade.

É necessário que a sociedade compreenda o idoso não como um sujeito incapaz, dependente ou impossibilitado. Atualmente, essa visão estereotipada do idoso já está ultrapassada visto que muitas pessoas ao chegarem em uma idade mais avançada continuam independentes, com capacidade e vontade de, mesmo após se aposentarem, atuar em trabalhos 
voluntários, informais ou até mesmo ajudar em casa com algumas tarefas, tais como cozinhar ou cuidar dos netos, por exemplo, de forma que seus familiares possam trabalhar fora de casa em serviços remunerados.

O Relatório Mundial sobre Envelhecimento e Saúde da OMS (2015) recomenda mudanças na maneira de formular políticas em saúde para atender àqueles que estão envelhecendo com serviços de qualidade e destaca que a tecnologia pode e vem sendo uma ferramenta de auxílio no envelhecimento, uma vez que permite peripécias como ficar conectado com a família quando distantes ou mesmo ter acesso a informações na internet sobre autocuidado. Além disso, aparelhos, como os auditivos, têm sido criados e aprimorados de modo a proporcionar maior qualidade de vida.

Segundo Veras (2012), o aumento da expectativa de vida e, consequentemente, o número crescente de idosos levará a um aumento da utilização dos serviços de saúde e essa demanda será um dos maiores desafios para o Brasil, pois serão necessários maiores investimentos no setor. De acordo com o autor, é necessário findar com a orientação que se tem atualmente no âmbito da saúde, onde o foco é a doença já estabelecida em detrimento das ações de prevenção.

As ações de prevenção são diversas e ao contrário do que se pode pensar não precisam ser complexas. Atividades esportivas, sociais ou de lazer, por exemplo, podem trazer inúmeros benefícios para a qualidade de vida do idoso e são oferecidas com copiosidade em municípios e cidades pelo país inteiro, enquanto que para idosos com maior grau de dependência ou limitação ou fragilizados por alguma doença atividades de suporte e apoio são escassas.

Varoto (2005) aponta que atividades em que há uma participação ativa do idoso possibilitam a este uma vida prazerosa e sem isolamento. Entretanto, o que se percebe é que idosos que por alguma razão não são independentes ou tornam-se dependentes, acabam deixando de participar de atividades como as mencionadas e é aí que está o fator de complexidade, pois há uma profunda necessidade de se fazer com que conhecimentos acerca do envelhecimento se aproximem da realidade da sociedade, para que a sociedade ampare o idoso em um momento de dependência.

Nem todas as famílias têm condições emocionais, físicas ou financeiras para dar o apoio necessário ao idoso e por terem outros compromissos e obrigações cotidianas, às vezes, o idoso acaba por ficar isolado dentro da própria casa. Muitas famílias buscam recursos alternativos para tentar solucionar essa questão e garantir que o idoso seja melhor assistido. Quando isso é necessário, a contratação de cuidadores em domicílio ou ILPIs são alternativas 
reais. E ainda há as situações em que essas são as únicas opções como nos casos em que o idoso não tem família ou tem dificuldades de se cuidar sozinho.

\section{NOÇÕES DE SAÚDE E POLÍTICAS DE CUIDADOS PARA IDOSOS}

O conceito de saúde é amplo e não pode ser visto como mera ausência de doença. Há inúmeras correntes de pensamento e nenhuma delas poderá dar uma definição fechada, uma vez que saúde é um fenômeno dinâmico e particular. Há que se considerar a representação que cada sujeito tem do que seja a saúde ou a enfermidade. Para idosos entrevistados por Pestana e Espírito Santo (2008), o importante é não ter doenças.

Envelhecer não é sinônimo de adoecer. Porém, é necessário que se tome diversos cuidados nesta fase da vida, dada sua predisposição biológica para certos agravos, como doenças crônicas. Infelizmente, as políticas públicas são imediatistas e curativistas. Na realidade, a demanda de certos cuidados específicos e permanentes requer uma equipe multiprofissional e especializada, incluindo a participação do psicólogo. Uma das alternativas para estes casos acaba sendo a Instituição de Longa Permanência para Idosos (ILPIs).

Estudos no país revelam que $85 \%$ dos idosos apresentam uma doença crônica, mas a maioria é capaz de organizar-se sem necessidade de auxílio. Cerca de $40 \%$ dos idosos com mais de 65 anos precisam de auxílio pra realizar algumas tarefas como compras ou cuidar do lar. Cerca de $10 \%$ precisa de ajuda para realizar tarefas básicas como tomar banho, alimentarse ou levantar da cama (SILVESTRE; COSTA NETO, 2003).

A partir da década de 80, quando a velhice deixou de ser considerada doença, surgiram diversas instituições com o intuito de ofertar cuidados integrais aos idosos. Uma delas é o asilo, hoje denominado Instituição de Longa Permanência para Idosos. No entanto, ainda existe uma visão negativa sobre essas instituições, sendo consideradas como sinônimos de abandono, uma vez que inicialmente proveem apenas as condições objetivas para a sobrevivência.

Cuidar demanda disposição, sacrifício, envolvimento emocional, gastos financeiros e um investimento de energia àquele que precisa do cuidado. Devido às mudanças de comportamento e possíveis perdas cognitivas na terceira idade, o cuidado não pode ser uma atividade meramente ética ou humanitária. É preciso que se capacite e se especialize para que se cuide em boas condições. No entanto, na falta de recursos financeiros para que se contrate um cuidador ou cuidadora de idosos, este serviço em geral recai sobre um membro da família, quase sempre mulher ou vizinha próxima. (KÜCHEMANN, 2012). 
Em nosso país, faltam políticas que amparem ou apoiem as famílias, os idosos dependentes e seus cuidadores. Para um cuidado de qualidade, sem retirar os idosos do convívio de seus lares, seria necessário haver orientação, capacitação e supervisão dos mais variados profissionais de saúde. Há que se pensar também no impacto que tal função causa na vida dos cuidadores, muitos deles também idosos e por vezes adoecidos.

No caso dos idosos que moram sozinhos, isto não necessariamente significa abandono ou solidão. Na realidade, pode ser uma forma saudável de envelhecimento, representando autonomia, contanto que possuam boa situação financeira e saúde (KÜCHEMANN, 2012).

É necessário que se desenvolvam ações inovadoras que supram as carências das políticas de saúde que atendem aos idosos. Elas devem prevenir possíveis males. Dentro desta perspectiva, a musicoterapia é uma excelente ferramenta para a promoção de saúde. O objetivo deve ser sempre a manutenção da saúde, em uma vida ativa e digna, com autonomia e independência.

\section{MUSICOTERAPIA: UMA ALTERNATIVA EM SAÚDE}

A musicoterapia é utilizada desde a antiguidade, embora ela seja tão recente quanto à Ciência. Oliveira (et al., 2012) apontam que em 1500 a.C., médicos egípcios consideravam que as mulheres podiam ter suas fertilidades aumentadas através da terapia musical. Nessa mesma época, os filósofos Aristóteles e Platão e, também, o médico Esculápio acreditavam que a mente era beneficiada pela música.

Em meados do Séc. XX, soldados dos EUA atingidos na guerra, receberam tratamento para depressão cuja terapêutica envolvia recursos musicais. Essa experiência estabeleceu-se como um marco e, a partir dos resultados observados, iniciou-se uma série de pesquisas sobre os benefícios que a música poderia causar à saúde. Em decorrência disso, surge o primeiro tratado em musicoterapia escrito por Richard Brocklesby em 1749. E, com o avanço dos estudos, a musicoterapia foi reconhecida como ciência contribuindo para a melhora física, psicológica e social dos indivíduos a ela submetidos.

Segundo Cunha (2003 apud OLIVEIRA et al., 2012), a música é uma forma de comunicação e expressão universal. E seus elementos são constituídos de muitas diversidades. Já Blasco (et al., 2003 apud OLIVEIRA et al., 2012) trazem o entendimento de que a música é uma linguagem universal marcando presença nas diferentes épocas e culturas. E afirmam que a Teoria Modal dos Gregos apresenta a música dividida em três elementos básicos: 
melodia, harmonia e ritmo. E esses elementos possuem o poder de causar alterações na fisiologia humana.

Rudd (1990 apud OLIVEIRA et al., 2012), diz que nos primórdios a doença era reconhecida como proveniente de influências malignas e sobrenaturais e, por isso, as intervenções religiosas eram utilizadas como meio de cura e, nesse processo, eram exploradas a música e a dança. Esses recursos ainda são utilizados nos dias atuais, por determinados grupos de índios, pois eles crêem que os maus espíritos são expulsos através da música. Dessa forma, o autor reafirma que "durante toda a história da humanidade, a música foi vista como um forte poder terapêutico [...]" (Id., p. 87).

A música volta a ser parte integrante das questões médicas no Séc. XVII, período do Renascimento, sendo aplicada em casos psiquiátricos, havendo registro de grande eficácia nesse tipo de tratamento.

Nesse Século, estudos realizados por Sacks (2007 apud OLIVEIRA et al., 2012) afirmam que para ocorrer a interação dos variados elementos da música (ritmo, harmonia, timbres e tons) considerável parte do cérebro é acionada, pois a música age no sistema nervoso autônomo. Dessa forma, torna-se capaz de eliminar a dor e diminuir o estresse contribuindo na redução do uso de analgésicos.

De acordo com os escritos de Padilha (2008 apud OLIVEIRA et al., 2012), em pacientes idosos, a influência musical se estabeleceu como fator de grande importância para assegurar melhor qualidade de vida, pois alcança as instâncias motora e cognitiva, além de promover a expressão de sentimentos, dando maior possibilidade de interação social, bem como o refletir sobre a própria vida.

Para Lapage (2011) e Bergel (2007) ambos citados por Oliveira (et al., 2012), a musicoterapia age como um benzodiazepínico, ${ }^{4}$ considerando a questão da diminuição da ansiedade. E para Cassileth, Vickers, Magill (2003 apud OLIVEIRA et al., 2012), a musicoterapia, em paciente submetidos a tratamento com altas doses de quimioterapia, contribui para a redução dos distúrbios de humor.

Blasco (et al., 2002 apud OLIVEIRA et al., 2012) diz que a música, além de ser importante na socialização, tem o poder de despertar efeitos psicológicos que proporcionam o aflorar das emoções, estimula a criatividade, melhora o nível de raciocínio e facilita a aprendizagem porque grande número de neurônios são ativados através do contato auditivo.

\footnotetext{
${ }^{4}$ Fármacos semelhantes à diazepina, us. em medicina por suas propriedades ansiolíticas.
} 
No campo dos transtornos mentais, a musicoterapia tem seu lugar marcado através da comunicação não verbal entre os pacientes, provocando melhor socialização entre eles.

Para que a musicoterapia apresente um resultado terapêutico esperado, Sacks (1997 apud OLIVEIRA et al., 2012) traz uma informação importante: é fundamental que as músicas utilizadas façam parte do gosto musical dos pacientes, porque, assim sendo, eles irão interagir de forma surpreendente através da dança, do canto e das expressões espontâneas que certamente surgirão. A interferência musical permite estabilidade, controle, sincronismo, facilidade para falar e realizar movimentos complexos.

Leão e Silva (2004 apud OLIVEIRA et al., 2012) entenderam, através de suas pesquisas, que a música alcança as dimensões biológica, mental, emocional e espiritual dos indivíduos, sobretudo, dos idosos. E por assim ocorrer, abrange o mecanismo de ação no controle da dor, por sua capacidade de induzir o relaxamento, liberar endorfina e provocar distração. A música pode provocar a mudança do foco perceptual da dor através da criação de imagens mentais provenientes da lembrança despertada e, assim, criar um elo entre percepção, emoção e mudança corporal.

Como visto, é amplo o benefício que a musicoterapia pode proporcionar como tratamento terapêutico.

\section{O PROJETO "VIDAS QUE TOCAM"}

\section{ETAPAS INICIAIS E METODOLOGIA}

O Projeto aconteceu ao longo de um semestre letivo, cumprindo duas fases distintas: a preparação teórica das equipes, incluindo visitação à Instituição de Longa Permanência para Idosos para reconhecimento do ambiente (ocorridos em três domingos consecutivos) quando as equipes realizaram visitas aos idosos acolhidos com a intenção de, nesta fase, construir a formação de vínculos através de uma escuta informal da história dos acolhidos indicados pelo psicólogo da Instituição e, a parte prática propriamente dita.

Na parte prática, já com a possibilidade de algum vínculo estabelecido, foi realizado um levantamento da memória emocional dos acolhidos, enfocando os seguintes pontos: a) $\mathrm{O}$ que o idoso fazia quando era mais novo? b) Que música marcou sua trajetória de vida? c) Quais são suas melhores lembranças? d) Que música relaciona a época dessas experiências (memórias)? Etc. 
O projeto ocorreu durante o horário aberto à visitação devido às possibilidades de haver mais pessoas na Instituição que poderiam ajudar nas etapas iniciais, inclusive, na busca de uma biografia musical considerando que os laços sociais ali estabelecidos eram de significativa relevância. A maioria das idosas acolhidas não recebiam visitas familiares em razão de não terem mais parentes vivos (visto que algumas já alcançaram seus 97 anos) ou em razão de os vínculos familiares terem se afrouxado e não mais haver interesse da família em manter contato.

Por três semanas consecutivas a equipe conversou com todas as idosas, no grande salão (local de convivência principal) ou mesmo nos quartos, pois algumas delas estavam acamadas, cansadas ou com dores, não se entremeando nas áreas comuns da Instituição.

Ao final de três semanas foram selecionados três grupos de idosas e a seleção foi feita de acordo com a capacidade, disponibilidade e receptividade dessas senhoras e com apoio e auxílio do psicólogo da Instituição. Isso porque haviam portadoras de deficiência auditiva e outras que não queriam participar, conversar, falar de si ou de música, ouvir música ou até mesmo parar de assistir TV por alguns instantes para dedicar sua atenção à equipe do projeto. Outras, por sua vez, se mostraram entusiasmadas com a proposta nas entrevistas iniciais.

Os grupos de idosas foram criados baseados também em interesses musicais semelhantes, um fator importante já que o projeto também consistia de sessões de musicoterapia em grupo.

Entretanto, antes da musicoterapia em grupo, exploramos de forma individual com as próprias idosas e com visitantes (amigos, parentes ou voluntários) as biografias musicais das idosas, buscando retornar tempos já longínquos de sua infância e adolescência bem como músicas mais tocadas em outra época e que costumavam ouvir em bons ou maus momentos de qualquer fase da vida.

Por vezes foi simples extrair nomes de músicas ou artistas preferidos delas, mas nem sempre. Algumas ficaram demasiadamente caladas e não recebiam visitas. Não mencionaram sequer uma canção ou cantor favorito. Com estas idosas a equipe se preocupou em realizar um percurso na linha do tempo de acordo com a data de nascimentos delas (obtidas pelo prontuário).

Com a biografia musical de cada uma das idosas, adquirida a partir das informações colhidas, as músicas foram postas em tablet ou smartphone e ouvidas por headphones com o volume de som devidamente ajustado conforme necessário.

Foram três semanas de contato individual com as músicas, numa etapa denominada 'Inundação', onde as equipes realizaram sessões de musicoterapia com base nas biografias 
musicais. Nessa etapa, todo tipo de reação (positiva ou negativa) era observada, indagada e anotada pelas equipes nos prontuários, uma vez que, em sua maioria, eram reações desencadeadas por lembranças que revelavam fatos importantes da história de vida delas e, ao anotar essas informações, suas histórias não se perderiam com as possíveis desordens que poderiam acometê-las com o avançar da idade.

$\mathrm{Na} 7^{\mathrm{a}}$ semana, momento denominado 'Desdobramento', as equipes efetuaram algumas técnicas de relaxamento em grupo (música clássica), Bailes, Dança circular, Cirandas, etc., ainda buscando conhecer e investigar as razões das manifestações de afeto que as idosas haviam vivenciado após a exposição das músicas, de forma a compreender o que significava essa ou aquela canção na vida daquelas senhoras ou se as canções faziam-nas recordar algo.

E por fim, na $9{ }^{\text {a }}$ semana, o 'Encerramento' do Projeto avisando às acolhidas sobre a interrupção das atividades pelas equipes e anunciando a chegada de outras equipes posteriormente.

Adiante, três experiências na ILPIs em Nova Friburgo/RJ serão descritas, de forma breve, visando apontar resultados relevantes, os quais tonaram-se objeto de análise neste artigo.

\section{EXPERIÊNCIA DA EQUIPE 1}

Na primeira sessão de musicoterapia uma das idosas de 94 anos, que havia passado os encontros anteriores muito séria e sem dizer muito, se mostrou aparentemente impressionada com o tablet e chegou a perguntar apontando para ele: "Nossa, muito, muito, muito bom. Que beleza! Você tem todas as músicas nesse rádio. Isso compra, né? Como faço para ter um?” e no desenvolvimento da musicoterapia logo mostrou outra feição. Ao ouvir Lady Laura, canção de Roberto Carlos, que ela não pediu mas que levamos por ser uma música que faz parte de sua época, sem demora passou a falar de algumas memórias e, ao falar delas, falava com um grande sorriso no rosto. Ao acabar a música se prontificou a falar sobre si, sobre sua vida antes da ILPIs, sobre a Instituição, como era permanecer ali, como eram as cuidadoras, etc. Ela estava ali há alguns anos e a ILPIs não tinha essas informações que ela contou à equipe e a equipe por sua vez não havia conseguido essas informações durante as três semanas anteriores nas tentativas de conversa com ela e de repente, através de uma canção ela se permitiu falar sobre si mesma.

Outro momento significativo foi com outra senhora de 97 anos, com prejuízo cognitivo e dificuldades nas funções executivas, na fala e na língua. Entretanto, apesar dessas 
e outras dificuldades, se mostrava sempre muito feliz. Ao ouvir Zezé di Camargo e Luciano (cantores que ela pediu para ouvir), ficou por uns momentos séria e aparentemente com os pensamentos voltados para outro lugar. A música, O último julgamento (de Léo Canhoto e Robertinho) foi levada para ela como uma surpresa considerando que é uma música de sua época e ela poderia reconhecer, e foi o que aconteceu. Ela cantou a música do início ao fim e isso foi um resultado espetacular, visto que trata-se de uma senhora que não dialogava com a equipe (devido às suas dificuldades de linguagem e cognitivas), ela apenas balbuciava e dizia palavras curtas, e vê-la cantando uma letra complexa inteira foi um momento emocionante. Uma outra senhora, de 74 anos, em uma das sessões de musicoterapia, estava com dor no joelho e, por isso, estava deitada na cama de seu quarto. Ela pediu para ouvir Zezé di Camargo e Luciano (porque era fã deles), Roberto Carlos, Roberta Miranda e Alcione e ao ouvir esses artistas foi um misto de emoções. Ao ouvir, Índia (de Roberto Carlos) ela fícou muito séria e com o olhar distante e nos disse "Isso dá saudade de muita coisa" e reconheceu uma canção de Roberta Miranda no primeiro acorde e já abriu um enorme sorriso. Ao ouvir, Você me vira a cabeça (de Alcione), uma canção que ela pediu que levássemos, se emocionou mas não quis dizer porquê. No fim da sessão, ela agradeceu e disse que não estava mais sentido a dor intensa que sentia no joelho e que estava "em paz".

As três senhoras foram reunidas para a musicoterapia em grupo com a finalidade de criar, aprofundar e estimular a interação social. Nesse grupo havia um aspecto em comum: Todas eram católicas. Diante disso, ao reuni-las foram apresentadas algumas canções religiosas como, Jesus Cristo (de Roberto Carlos) e Ave Maria (de Chitãozinho e Xororó). Todas ficaram muitas atentas às letras e nada falavam. Fechavam os olhos e tinham um semblante sereno, como se aquele momento estivesse de fato sendo apreciado.

Entretanto, em um outro encontro em grupo, onde foram apresentadas novas canções, incluindo cantigas de roda com o intuito de despertar sentimentos e memórias infantis, nem todas apreciaram a ideia. Uma delas optou por sair do grupo e ficar sozinha depois de ter dormido durante as primeiras canções. Todavia, as outras desfrutaram da oportunidade de fazer algo novo e em grupo e se divertiram com as cantigas.

No último encontro a equipe colocou todas as três juntas novamente e foi comunicado que esse seria o último encontro do projeto com a nossa equipe mas, que o projeto seria continuado por outras equipes. Dessa forma elas poderiam continuar participando se assim quisessem. O projeto foi encerrado com as canções que mais despertaram emoções nelas. Apesar de ter sido positiva a experiência em grupo para algumas, foi possível perceber que a musicoterapia individual trouxe maiores benefícios e de diferentes esferas, 
como recuperação de lembranças há muito esquecidas, sensação de bem-estar, de alegria e alívio de dores.

\section{EXPERIÊNCIA DA EQUIPE 2}

Uma das três senhoras acompanhadas pela equipe sofria de Alzheimer e estava sempre na sala de estar assistindo TV. Nunca se lembrava da equipe quando esta chegava ou a confundia com outras pessoas. Essa senhora sempre contava sua história de maneiras diferentes, às vezes se perdendo no tempo e, às vezes, achando que seus filhos (já adultos) ainda eram crianças. Em uma das visitas, a equipe pode conversar com um de seus filhos, que falou um pouco do passado dela e revelou algumas músicas e cantores que ela gostava. A equipe levou algumas canções para ela mas ela não teve paciência de ouvi-las até o fim e nem de usar os headphones. Tampouco reconheceu o que ouvia.

A segunda senhora estava de cama em um quarto, pois havia quebrado o fêmur. Estava perfeitamente lúcida e nos contou sobre seu passado religioso no convento. Em uma das visitas a equipe encontrou sua amiga de infância e seu irmão, e juntos começaram, espontaneamente, a relembrar o passado e a cantar cantigas de roda da época. Esse momento foi aproveitado pela equipe para anotar as letras e pesquisá-las depois. Nos encontros seguintes, ela encantou-se ouvindo as letras e cantou junto. Ouvi-las novamente despertou-lhe memórias e histórias. No dia de fazer o relaxamento com música clássica, foi instruída a respirar calmamente. E foi realizado com ela uma visualização. Ela escolheu se imaginar andando pela brisa fresca num gramado à beira de um lago, e ficou com os olhos marejados, dizendo que nunca tinha feito algo daquele tipo e que estava encantada.

A terceira senhora era uma cadeirante e, por vezes, manifestava alguns sintomas aparentemente paranóicos, pois achava que poderia estar sendo perseguida. No primeiro encontro, desconfiou do caderno de anotações da equipe, achando que estávamos fazendo anotações para a polícia. Por vezes, começava a falar sobre determinadas personalidades políticas ou históricas e a narrar críticas e ameaças revoltadas a elas. Por ser muito sincera e autêntica em suas afirmações, era muito divertida. Adorou relembrar conosco os nomes dos cantores de seu passado. Quando levamos as canções, cantava junto, com uma bela voz, e comentava elogios a certos trechos de músicas, achando que também estávamos ouvindo o som que saía do headphone. Começou a lembrar-se de cenas trágicas do passado e preferiu não falar muito sobre. Não teve muita paciência para relaxamento, até mesmo por ser desconfiada. 
No último encontro, reunimos as três no quarto da senhora acamada. Colocamos algumas cantigas de roda e músicas da época delas. A primeira senhora, da sala de TV, desejava sair dali para ir fazer outra coisa. A senhora desconfiada mandou que um de nós calasse a boca para que ela tentasse reconhecer a música. A senhora acamada permaneceu em silêncio apreciando as canções. Personalidades distintas com alguns sintomas distintos resultaram em uma curiosa e engraçada interação.

\section{EXPERIÊNCIA DA EQUIPE 3}

Inicialmente, três senhoras se dispuseram a participar das atividades dessa equipe. Porém, uma delas desistiu logo no início, pois dormia a maior parte do dia. Uma outra precisou parar em razão de um problema de saúde durante o projeto. Logo, a equipe deu sequência com a única senhora restante já que não houve interesse de outras idosas acolhidas em participar do trabalho.

No primeiro encontro, a vivência do projeto musical foi emocionante em razão de ter sido notável o exato momento em que essa senhora foi envolvida com a intervenção musical realizada. Ela retornou ao passado tornando quase possível à equipe acompanhá-la nessa aventura. A música La vie en Rose, sugestão dada por ela nas visitas anteriores, foi apresentada e sua expressão facial foi alterada no decorrer da canção. Além da expressão facial, o movimento corporal, o cantar junto, o aplaudir empolgado, o segurar as mãos com firmeza, o olhar fixo para o aparelho de som como se fosse ele o cenário do que um dia ela viveu relacionado à música que ali tocava.

No segundo encontro outras três senhoras, espontaneamente, se juntaram a ela em seu quarto e depois mais outras três se achegaram atraídas pelo som da música. Porém, a senhora foco dessa equipe não se recordou da equipe, por isso, se apresentou novamente perguntando pelo nome de cada integrante. Aos 97 anos, o início do Alzheimer parecia estar se instalando, embora os profissionais da ILPIs informaram que o diagnóstico não estiva fechado, contudo, havia essa possibilidade, porque a falta de memória apresentada poderia ser atribuída também à idade avançada.

Na semana seguinte a equipe levou a música La Bohème, sugerida por ela. Foram também apresentadas, músicas de Roberto Carlos, apesar de gostar dessas, não causaram impacto sobre ela. E ao ouvir novamente a música La vie en Rose, ela repetiu (reviveu) as reações manifestadas na primeira semana. Para essa senhora, era como se fosse essa a 
primeira experiência com essa música e repentinamente ela agradece nossa visita e manifesta o desejo de dirigir-se ao quarto.

No terceiro encontro a equipe não trabalhou com música, foi respeitado o interesse manifestado por ela de permanecermos na varanda para uma 'boa conversa'. Novamente se apresenta de forma educada e gentil, ficando claro para a equipe que ela não se recordava dos últimos encontros. Contou-nos sobre parte de sua vida, suas viagens, seu casamento e atividades que desempenhava no passado. Falou do quanto gostaria de ser útil para outras pessoas, mesmo ali na Instituição gostaria de passar seus conhecimentos em tantas áreas distintas. Exemplificou citando o tricô como sendo uma das atividades que poderia ensinar e, também a alfabetização que poderia ser feita a partir de pequenos objetos já conhecidos pelas acolhidas. Falou da ociosidade em que vivem as mulheres ali na Instituição por não haver interesse delas em aprender algo, esboçou certa mágoa por isso. Em seguida, um desabafo: não há ninguém ali com quem poderia manter uma boa conversa, por isso, recorre aos livros da biblioteca.

No encontro seguinte, foi apresentado um texto, em francês, pois tratava-se de uma senhora poliglota e, por isso, tentamos explorar essa habilidade introduzindo algo sobre a Ópera La Bohème e um outro texto sobre a vida de Joana D'Arc e outra vez ela se apresenta de forma gentil, tentando prontamente traduzir o texto achando que esse era o objetivo de estarmos ali naquela tarde. Prontamente se empenha para nos apresentar uma boa tradução. Então, pergunta porque estávamos precisando da tradução. Informamos que os trouxemos para ela ler quando desejasse. Gentilmente agradeceu nossa dádiva, sem se dar conta de que foi algo combinado na semana anterior.

Com essa senhora houve a possibilidade do Projeto ter um desdobramento após seu anunciado encerramento. Houve a tentativa, com significativo grau de sucesso inicial, de conduzi-la ao Theatro Municipal do Rio de Janeiro para assistir uma Ópera. Contudo, a viagem foi interrompida no meio do caminho por decisão dela própria, pois nesse dia seu humor estava consideravelmente alterado e, por isso, toda sua empolgação para essa atividade se esvaiu. Entretanto, foi uma rica e produtiva experiência acadêmica até ao ponto em que conseguimos alcançar. Essa senhora faleceu na Instituição poucos meses após ocorrida a experiência do Projeto e exatamente conforme ela sempre dizia para nós: "Eu sei que eu irei morrer aqui". 


\section{CONSIDERAÇÕES FINAIS}

Este artigo abordou noções de saúde e política de cuidados ao idoso de modo a trazer luz sobre uma população que cresce exponencialmente em nosso país (e no mundo) e que tem ficado relegada aos modelos de saúde curativistas e imediatistas, um modelo que não se propõe a repensar possibilidades de intervenção e promoção de saúde a médio e longo prazo. É preciso um movimento no sentido contrário para que se evite que problemas e desordens já previstos anteriormente continuem a ocorrer ou a se intensificar.

Este artigo traz a intenção de propor um investimento em estratégias de prevenção, pois existem diversas alternativas que podem contribuir para um envelhecimento mais saudável e com qualidade. Porém, boa parte da população ainda não tem acesso às diversas alternativas por razões variáveis. E, justamente por não ter acesso a esses serviços, essa parcela fica mais suscetível aos agravos de saúde na velhice. É em função de tais agravos que o idoso pode vir a perder sua autonomia e passar a depender de familiares em tarefas simples. Quando a família não tem as condições necessárias para oferecer tal cuidado, a alternativa passa a ser a internação em uma ILPIs.

Nossa sociedade é marcada por uma imagem estereotipada de idoso. O idoso é visto ou tido como um sujeito doente, sem autonomia, frágil, incapaz, impossibilitado, vulnerável, um peso, etc. É verídico que o processo de envelhecimento acarreta em mudanças biopsicossociais. Entretanto, com políticas de saúde voltadas para a qualidade de vida e para promover um envelhecimento ativo, o sujeito, ao envelhecer, terá melhores condições de seguir sua vida de forma independente, necessitando de cuidados como qualquer outra pessoa.

Também foi apresentado aqui uma síntese da experiência prática do Projeto: "Vidas que Tocam", resultado de um Projeto de Extensão da Universidade Estácio de Sá, Campus Friburgo (RJ), com intuito de minimizar um desafio que perpassa os cursos universitários de diferentes áreas: aproximar as teorias à realidade.

O Projeto alcançou êxito na ILPIs ao conseguir o que se pretendia: resgatar lembranças da história de algumas idosas acolhidas pelo viés da musicoterapia, apresentada como uma terapia alternativa, proporcionando agradáveis recordações, distração, relaxamento e bem-estar às idosas institucionalizadas possibilitando um vislumbre na memória de uma época por elas bem vivida.

$\mathrm{O}$ artigo foi escrito na esperança de que ele seja um instrumento de incentivo aos profissionais da saúde, no sentido de buscarem medidas que venham a auxiliar na prevenção e tratamento de doenças dos idosos, proporcionando uma melhor qualidade de vida. Como 
visto, a musicoterapia, com suas atividades expressivas musicais, torna-se um excelente meio de contribuição na saúde do idoso, pois os distúrbios que acometem essa faixa etária alcança melhora clínica com essa terapêutica. Sem contar a participação ativa deles tornando o convívio com seus pares mais prazeroso, o que é visto também como grande ganho promovido pela ação da musicoterapia.

\section{REFERÊNCIAS}

ALBUQUERQUE, Maria Cícera dos S. et al. Os efeitos da música em idosos com doença de Alzheimer de uma instituição de longa permanência. (Publicado em Alagoas, 2012). Disponível em: https://www.fen.ufg.br/fen_revista/v14/n2/v14n2a21.htm Acesso em: 16 maio 2016.

BARROS, Rodrigo Heleno de; GOMES JUNIOR, Edmundo de Paula. POR UMA HISTÓRIA DO VELHO OU DO ENVELHECIMENTO NO BRASIL. CES Revista, [s.l.], v. 27, n. 1, p. 75-92, jun. 2015.

CAMÕES, Cristina; PEREIRA, Fernanda Marie; GONÇALVES, Andréa. Reabilitação na Doença de Alzheimer. (Portugal, 2005). Disponível em: http://www.psicologia.pt/artigos/textos/A0244.pdf Acesso em: 16 maio 2016.

CORTÊ, B; NETO, P. L. A musicoterapia na doença de Parkinson. UAEM. São Paulo, 2008. Disponível em: http://www.redalyc.org/html/630/63012431036/ Acesso em: 17 mar. 2018 .

CUNHA, Rosemyriam. Musicoterapia na Abordagem do Portador de Doença de Alzheimer. (Paraná). Disponível em: http://meloteca.com/musicoterapia2014/musicoterapiana-abordagem-do-portador-de-alzheimer.pdf Acesso em: 16 maio 2016.

GEIB, Lorena Teresinha Consalter. Determinantes sociais da saúde do idoso. Ciênc. saúde coletiva. Rio de Janeiro, v. 17, n. 1, p. 123-133, Jan. 2012.

KUCHEMANN, Berlindes Astrid. Envelhecimento populacional, cuidado e cidadania: velhos dilemas e novos desafios. Soc. estado, Brasília, v. 27, n. 1, p. 165-180, Abr. 2012.

LIMA-COSTA, Maria Fernanda; BARRETO, Sandhi Maria; GIATTI, Luana. Condições de saúde, capacidade funcional, uso de serviços de saúde e gastos com medicamentos da população idosa brasileira: um estudo descritivo baseado na Pesquisa Nacional por Amostra de Domicílios. Cad. Saúde Pública. Rio de Janeiro, v. 19, n. 3, p. 735-743, Jun. 2003.

OLIVEIRA, Glauber C. et al. A contribuição da musicoterapia na saúde do idoso. (Volta Redonda, RJ: 2012). Disponível em: http://web.unifoa.edu.br/cadernos/edicao/20/85-94.pdf Acesso em: 16 maio 2016.

OMS. Envelhecimento ativo: uma política de saúde. World Health Organization. Tradução de Suzana Gontijo - Brasília, DF: Organização Pan-Americana da Saúde, 2005. 60p.:il. 
Disponível em: http://bvsms.saude.gov.br/bvs/publicacoes/envelhecimento_ativo.pdf. Acesso em: 17 mar. 2018.

OMS. Relatório Mundial sobre Envelhecimento e Saúde. 2015. 30p. Disponível em: http://sbgg.org.br/wp-content/uploads/2015/10/OMS-ENVELHECIMENTO-2015-port.pdf Acesso em: 17 mar. 2018.

PESTANA, Luana Cardoso; ESPÍRITO SANTO, Fátima Helena do. As engrenagens da saúde na terceira idade: um estudo com idosos asilados. Rev. esc. enferm. USP, São Paulo, v. 42, n. 2, p. 268-275, Jun. 2008.

SANTANA, D. S. T. et al. Efeitos da música e da musicoterapia na pressão arterial: Uma revisão de literatura. InCantare: Rev. do Núcleo de Estudos e Pesquisas Interdisciplinares em Musicoterapia. Curitiba, p. 37-57, v. 5, 2014. Disponível em: http://periodicos.unespar. edu.br/index.php/incantare/article/view/261/pdf_9. Acesso em: 17 mar. 2018.

SILVESTRE, Jorge Alexandre; COSTA NETO, Milton Menezes da. Abordagem do idoso em programas de saúde da família. Cad. Saúde Pública. Rio de Janeiro, v. 19, n. 3, p. 839-847, Jun. 2003.

VAROTO, V. A. G. et al. Programas para Idosos independentes: um estudo sobre seus egressos e a prevalência de doenças crônicas. UAEM, 2005. Disponível em: http://www.redalyc.org/html/714/71413115/ Acesso em: 17 mar. 2018.

VERAS, R. P. Prevenção de doenças em idosos: os equívocos dos atuais modelos. Rio de Janeiro, out., 2012. Disponível em: https://www.scielosp.org/article/ssm/content/raw/? resource_ssm_path=/media/assets/csp/v28n10/03.pdf. Acesso em: 24 mar. 2018. 